\title{
Athletic Training Assessment of Knowledge Inconsistent with Perceptions of Knowledge Needs: Part II
}

\author{
Jessica R. Edler \\ Grand View University, jedler@grandview.edu \\ Lindsey E. Eberman \\ Indiana State University, leberman@indstate.edu
}

Follow this and additional works at: https://nsuworks.nova.edu/ijahsp

Part of the Medical Education Commons, and the Sports Sciences Commons

\section{Recommended Citation}

Edler JR, Eberman LE. Athletic Training Assessment of Knowledge Inconsistent with Perceptions of Knowledge Needs: Part II. The Internet Journal of Allied Health Sciences and Practice. 2020 Jan 01;18(1), Article 7.

This Manuscript is brought to you for free and open access by the College of Health Care Sciences at NSUWorks. It has been accepted for inclusion in Internet Journal of Allied Health Sciences and Practice by an authorized editor of NSUWorks. For more information, please contact nsuworks@nova.edu. 


\title{
Athletic Training Assessment of Knowledge Inconsistent with Perceptions of Knowledge Needs: Part II
}

\begin{abstract}
Purpose: Continuing education (CE) is intended to promote continued competence beyond the level required for entry-level practice. Previous research suggests that athletic trainers are unable to identify their knowledge gaps regarding their clinical practice. The purpose of this research study was to determine if athletic trainers' perceived need for CE aligns with their performance on an actual knowledge assessment. Method: We used a correlational design conducted on Qualtrics, a web-based platform. Four hundred, forty-four (444) athletic trainers completed all the CE Needs Assessment and over $60 \%$ of the athletic training assessment of knowledge. The CE Needs Assessment determined participant's perceived need for CE using a 5-point Likert scale on the 8 content areas within the National Athletic Trainers' Association's educational competencies. The athletic training assessment of knowledge included 71 multiple-choice questions across the 5 domains of athletic training. Actual knowledge for each domain was determined by calculating the percent of correct answers within the domain. We used a Pearson's correlation analysis to determine the relationship between perceived need for CE and actual knowledge for each domain. Results: We identified a poor, negative, significant correlation between orthopedic clinical assessment and diagnosis $(r=-0.10, P=0.034)$ and domain 2 (clinical evaluation and diagnosis) total score. We also identified a poor, negative significant correlation between therapeutic interventions $(r=-0.10$, $P=0.04$ ) and domain 4 (treatment and rehabilitation). We identified non-significant correlations between perceived need for CE in evidence-based practice, prevention and health promotion, acute care of injury and illness, psychosocial strategies and referral, healthcare administration, and professional development and responsibility and their respective domain total scores. Conclusions: Athletic trainers are unable to consistently identify their need for $\mathrm{CE}$ in relation to their actual knowledge performance. This suggests that perceived need is not an effective means to identify areas of weakness in athletic training clinical practice and should not be used to guide CE choices.
\end{abstract}

\section{Author Bio(s)}

Jessica R. Edler is an Assistant Professor and the Clinical Education Coordinator of the Professional Masters Athletic Training program at Grand View University in Des Moines, IA She is also a licensed athletic trainer in the state of lowa.

Lindsey E. Eberman is a Professor and the Program Director of the Post-Professional Doctor of Athletic Training program in the College of Health and Human Services at Indiana State University in Terre Haute, IN. She is also a licensed athletic trainer in the state of Indiana. 


\title{
1IJAHSP \\ The Internet Journal of Allied Health Sciences and Practice \\ Dedicated to allied health professional practice and education
}

Vol. 17 No. 4 ISSN 1540-580X

\section{Athletic Training Assessment of Knowledge Inconsistent with Perceptions of Knowledge Needs: Part II}

\author{
Jessica R. Edler ${ }^{1}$ \\ Lindsey E. Eberman² \\ 1. Grand View University \\ 2. Indiana State University \\ United States
}

\begin{abstract}
Purpose: Continuing education (CE) is intended to promote continued competence beyond the level required for entry-level practice. Previous research suggests that athletic trainers are unable to identify their knowledge gaps regarding their clinical practice. The purpose of this research study was to determine if athletic trainers' perceived need for CE aligns with their performance on an actual knowledge assessment. Method: We used a correlational design conducted on Qualtrics, a web-based platform. Four hundred, forty-four (444) athletic trainers completed all the CE Needs Assessment and over $60 \%$ of the athletic training assessment of knowledge. The CE Needs Assessment determined participant's perceived need for CE using a 5-point Likert scale on the 8 content areas within the National Athletic Trainers' Association's educational competencies. The athletic training assessment of knowledge included 71 multiple-choice questions across the 5 domains of athletic training. Actual knowledge for each domain was determined by calculating the percent of correct answers within the domain. We used a Pearson's correlation analysis to determine the relationship between perceived need for $\mathrm{CE}$ and actual knowledge for each domain. Results: We identified a poor, negative, significant correlation between orthopedic clinical assessment and diagnosis $(r=-0.10, P=0.034)$ and domain 2 (clinical evaluation and diagnosis) total score. We also identified a poor, negative significant correlation between therapeutic interventions $(r=-0.10, P=0.04)$ and domain 4 (treatment and rehabilitation). We identified non-significant correlations between perceived need for CE in evidence-based practice, prevention and health promotion, acute care of injury and illness, psychosocial strategies and referral, healthcare administration, and professional development and responsibility and their respective domain total scores. Conclusions: Athletic trainers are unable to consistently identify their need for CE in relation to their actual knowledge performance. This suggests that perceived need is not an effective means to identify areas of weakness in athletic training clinical practice and should not be used to guide CE choices.
\end{abstract}

Keywords: knowledge gap, perceived knowledge, professional development

Editor's Note: Part I of this study was published in the October 2019 issue of this Journal under the title Comprehensive Knowledge Assessment for Athletic Trainers, Part I. 


\section{INTRODUCTION}

Continuing education (CE), according to the Board of Certification (BOC), is intended to promote continued competence beyond entry-level practice. ${ }^{1} \mathrm{CE}$ is one mechanism of formal learning used to promote continued competence and serves to help athletic trainers maintain current knowledge and develop new knowledge as new skills and/or techniques emerge. Additionally, CE (specifically the BOC's Evidence Based Practice approved sessions) provides athletic trainers the opportunity to learn about the evidence related to their current practices to improve patient care using evidence to drive decision making.

The need for CE and continued competence aligns with the Institute of Medicine (IOM) core competencies, more specifically the integration of evidence-based medicine and continuous quality improvement. The IOM core competencies were developed in 2001 as a broad set of skills that all healthcare professionals should demonstrate within their clinical practice. ${ }^{2}$ Continuous quality improvement focuses on the practitioner's responsibility to measure patient outcomes and compare their current practice to methods used elsewhere as a means to identify areas to improve patient care. ${ }^{2}$ For example, a clinician might compare how they manage a grade 3 lateral ankle sprain to a colleague whose patients are experiencing better outcomes, to determine areas of improvement in their current practice methods for that particular pathology.

Athletic trainers must be able to identify their knowledge gaps as clinicians. A knowledge gap is the relationship between what one believes he/she knows (perceived knowledge) and the knowledge he/she possesses (actual knowledge). Identifying a knowledge gap requires personal reflection and an assessment mechanism to determine the efficacy of their patient care. Clinicians could then use this information to drive their $\mathrm{CE}$ choices. However, research suggests that healthcare professionals struggle to accurately understand their knowledge gaps, including those in athletic training, nursing, and pharmacy. ${ }^{3-11,12}$ Additionally, researchers have also explored self-efficacy as a means to identify CE need, where self-efficacy is one's perception of their ability to successfully perform a specific skill or task. ${ }^{13,14}$ The researchers had similar findings to the perceived knowledge studies, suggesting healthcare professionals are unable to identify gaps in knowledge and skills, and therefore, may not seek CE sessions that address their knowledge gaps. Yet, the CE model of self-directed acquisition of credits without assessment continues to serve as our mode to maintain competence.

Athletic trainers' perceived need for CE has also been demonstrated in previous research. ${ }^{15}$ Athletic trainers were asked to rate their need for $\mathrm{CE}$ on 5-8 specific tasks within each of the 5 domains of athletic training. Overall, athletic trainers rated their need for $\mathrm{CE}$ to be some-moderate need for all 5 domains. ${ }^{15}$ The findings from this research suggest that athletic trainers believe they have need for $\mathrm{CE}$; however, no research has examined the accuracy of their perceived need for $\mathrm{CE}$ compared to actual knowledge across all domains of athletic training. Therefore, the purpose of this study was to determine if athletic trainers' perceived need for $\mathrm{CE}$ aligns with their score on a knowledge assessment.

\section{METHODS}

This study was deemed exempt by the Indiana State University Institutional Review Board prior to beginning this study.

\section{Design}

We used a correlational design to understand the relationship between perceived need for CE and actual knowledge in athletic trainers.

\section{Participants}

Certified athletic trainers ( $n=444$ ) completed all the CE Needs Assessment and over $60 \%$ of the Athletic Training Assessment of Knowledge (ATAK). Respondents were representative of the National Athletic Trainer's Associations' membership demographic characteristics (age $=32 \pm 9 \mathrm{yrs}$, years of experience $=9 \pm 8 \mathrm{yrs}$ ). ${ }^{16}$ Table 1 provides further participant demographic information.

\section{Procedures}

A random sample of athletic trainers were contacted via email to complete our online instrument. Athletic trainers were excluded if they had retired or held lapsed NATA membership. The email included a recruitment letter with the link to the online instrument that included the informed consent document, CE Needs Assessment, and the ATAK. Those who had not completed the study received email reminders to encourage participation each week for three weeks following the initial email. Four weeks after the initial email was sent, the study was closed.

\section{Instruments}

The need for CE was assessed using a 5-point Likert scale (1=no need, 2-little need, 3=some need, 4=moderate need, $5=$ substantial need). The CE Needs Assessment included the 8 content areas represented the educational competencies. ${ }^{17}$ We used a similar structure to the BOC Professional Development Needs Assessment, but considered that the domain headings 
Table 1. Participant Demographics $(\mathrm{N}=444)$

\begin{tabular}{lr}
\hline Characteristic & Frequency (\%) \\
\hline Sex & $136(30.6)$ \\
Male & $307(69.1)$ \\
Female & $1(0.3)$ \\
Other & \\
Current Clinical Setting & $145(32.7)$ \\
College/University & $149(33.6)$ \\
Secondary/lntermediate & $71(16.0)$ \\
Clinic/Hospital & $6(1.3)$ \\
Professional sports & $1(0.3)$ \\
Performing arts & $0(0.0)$ \\
Public Safety & $6(1.3)$ \\
Military & $6(1.3)$ \\
Occupational health & $60(13.5)$ \\
Other & \\
Highest Degree Earned & $128(28.8)$ \\
Bachelor's (BA, BS, etc) & $290(65.3)$ \\
Master's (MA, MS, etc) & $11(2.5)$ \\
Clinical Doctorate (DAT, DHS, DHSc, etc) & $15(3.4)$ \\
Academic Doctorate (PhD, EdD, etc) &
\end{tabular}

represented too few concepts, while each task represented too many to make the tool feasible. ${ }^{18}$ We considered alternative models and identified the educational competency areas that allowed us to explore respondent perceived CE need more broadly.

The ATAK was developed using seven expert item-writers who had been involved in the development of the $5^{\text {th }}$ edition of the educational competencies and other experts in the field of athletic training. Item-writers were solicited via email to write 20-30 questions based on their area of expertise. Areas of expertise were established by their respective participation in preparing the educational competencies $(n=6)$; clinical expertise was established through residency experience $(n=1)$. The ATAK was validated using item analysis and test re-test reliability. The final instrument consisted of 71 items across the 5 domains of athletic training and demonstrated high internal consistency (Cronbach's $\alpha=0.843$ ).

\section{Data Analysis}

We computed descriptive statistics on demographic variables to describe our participants. We utilized the BOC's crosswalk analysis to align the domains and content areas for analysis. ${ }^{19}$ We calculated analyses of central tendency for each content area on the CE Needs Assessment. We also calculated the percent of correct responses within each of the five domains of athletic training on the ATAK (Table 2). These scores were used to perform a Pearson's correlational analysis between perceived need for CE and actual knowledge, consistent with previous research looking at knowledge gap. ${ }^{3-8,10-12}$ Significance was set at $P<0.05$ a priori, two-tailed.

Table 2. Percent Correct on Athletic Training Assessment of Knowledge by Domain

\begin{tabular}{lcc}
\hline Domain & Percent Correct \pm SD & Total Questions within \\
& & Domain \\
\hline I - Injury/lllness prevention and wellness protection & $52.96 \pm 20.80$ & 8 \\
II - Clinical evaluation and diagnosis & $55.20 \pm 18.72$ & 21 \\
III - Immediate and emergency care & $55.26 \pm 19.12$ & 12 \\
IV - Treatment and rehabilitation & $60.90 \pm 21.87$ & 10 \\
V - Organizational and professional health and well-being & $49.59 \pm 18.76$ & 20 \\
\hline
\end{tabular}

\section{RESULTS}

Participants scored their need for CE to be "some" to "moderate" need for all content areas (Table 3). Overall participants scored poorly on the ATAK $(54.18 \% \pm 15.83 \%)$. Our participants scored the highest on the ATAK in the domain area of treatment and rehabilitation $(60.90 \pm 21.87 \%)$ and the lowest in organizational and professional health and well-being $(49.59 \pm 18.76 \%$; Table 2). 
Table 3. Perceived Need for Continuing Education by Content Area

\begin{tabular}{lc}
\hline Competency Area & $\begin{array}{c}\text { CE Need } \\
\text { Mean } \pm \text { SDa }\end{array}$ \\
\hline Evidence Based Practice & $3.36 \pm 1.04$ \\
Prevention and Health Promotion & $3.26 \pm 0.80$ \\
Clinical Examination and Diagnosis & $3.38 \pm 0.84$ \\
Acute Care of Injuries and Illnesses & $2.90 \pm 0.95$ \\
Therapeutic Interventions & $3.20 \pm 0.77$ \\
Psychosocial Strategies and Referral & $3.35 \pm 0.99$ \\
Healthcare Administration & $3.05 \pm 0.80$ \\
Professional Development and Responsibility & $3.14 \pm 1.04$ \\
\hline Scale: 1=no need, 2=little need, 3=some need, 4=moderate need, 5=substantial need
\end{tabular}

We identified weak, negative, significant correlations on two items, the first was between perceived need for CE of clinical examination and diagnosis and percent correct within domain II (clinical evaluation and diagnosis; Table 4). The second between perceived need for CE of therapeutic interventions and percent correct within domain IV (treatment and rehabilitation; Table 4). Additional correlation data for all other comparisons can be found in Table 4.

Table 4. Perceived Need for CE and Actual Knowledge Correlations

\begin{tabular}{lcc}
\multicolumn{1}{c}{ NATA Competency Area } & BOC Domaina & $\begin{array}{c}\text { Pearson's } \\
\text { Correlation } \\
\text { Coefficient }(r)\end{array}$ \\
\hline Evidence Based Practice & V & -0.09 \\
Prevention and Health Promotion & III & -0.06 \\
Clinical Examination and Diagnosis & II & -0.03 \\
Acute Care of Injuries and Illnesses & I & $-0.10^{\mathrm{b}}$ \\
& III & -0.02 \\
Therapeutic Interventions & IV & -0.04 \\
Psychosocial Strategies and Referral & II & $-0.10^{\mathrm{b}}$ \\
Healthcare Administration & V & -0.01 \\
Professional Development and Responsibility & I & -0.06
\end{tabular}

aDomain Names - I: Injury/lllness Prevention and Wellness Protection; II: Clinical Evaluation and Diagnosis; III: Immediate and Emergency Care; IV: Treatment and Rehabilitation; V: Organizational and Professional Health and Well-being b $P<0.05$

\section{DISCUSSION}

\section{Perceive and Actual Knowledge}

Results indicated weak and insignificant relationships between perceived need for $\mathrm{CE}$ and actual knowledge for injury prevention, nutrition, medical conditions, acute care of injuries, acute care of illnesses, therapeutic modalities, therapeutic interventions, pharmacology, risk management, healthcare administration, evidence-based practice, and professional development. While the relationship between orthopedic clinical assessment and diagnosis perceived need for CE and domain 2 AKAT score was significant, it was a very poor and negative relationship, meaning little to no relationship exists. Overall, these results suggest ATs cannot accurately appraise their actual knowledge, and most often they drastically overestimate their knowledge. This would suggest they are then underestimating their need for $\mathrm{CE}$, which aligns with previous research regarding knowledge gaps in athletic training..$^{3-6}$ The lack of relationship between perceived need for $C E$ and actual knowledge can be potentially dangerous for patients. Patients may be at risk when the clinicians treating them have either an inflated sense or a lack of confidence in perceived knowledge of their abilities. Overall, our participants suggested they had some need for CE in all content areas. However, their perceived need for CE was some to moderate, which suggests they are broadly aware that they possess a knowledge gap, but not to the extent consistent with the low ATAK performance. 
Previous research within self-efficacy, skill/task performance, and skill decay suggests a gap between self-efficacy and skill retention..$^{13}$ The combination of research within perceived knowledge and self-efficacy furthers the need for an assessment of actual knowledge and/or the ability to perform tasks/skills to determine where one's need for CE truly lies. Asking healthcare professionals to subjectively score their perceived knowledge or self-efficacy within the domains of athletic training or the educational competency areas is not an effective means for identifying their actual need for CE; it is just one piece in the quality improvement process.

\section{Knowledge and Competence}

The act of taking a test is least congruent with actual job performance on the spectrum of possible assessments of competence. ${ }^{20}$ Based on our findings and previous research, however, test taking is more effective than perceived knowledge alone. ${ }^{3-6,13,20}$ Test taking may serve the profession better if used to provide high quality feedback about an athletic trainer's areas of weakness and need for $\mathrm{CE}$ as compared to perceived knowledge and self-efficacy scores. Miller described a framework for clinical assessment that includes knowledge assessment at the bottom of the pyramid. ${ }^{21} \mathrm{He}$ himself cautions the use of knowledge assessments alone to determine a clinician's ability to provide patient care. He suggests a pyramid approach with knows (knowledge) at the bottom, knows how (competence) as the next tier, followed by shows how (performance), and finally does (action) at the top. ${ }^{21}$ Examples of assessments in each of these steps includes factual tests, clinical context based tests, mock performance assessment (OSCE or standardized patient), and performance assessment in real-time (undercover standardized patient or video), moving from the bottom of the pyramid to the top. ${ }^{22}$

If our theoretical framework stands true, this suggests that the way we, in AT, and those in other healthcare professions, engage in $C E$ that is not ensuring continued competence. An alternative approach to CE should be explored. One model that could serve to guide us is the maintenance of certification process used by the American Board of Medical Specialties. Although the American Medical Association has just recently opposed recertification exams because of the perceived burden on clinicians, there is something to be gained from this model. The maintenance of certification process is somewhat different for each subspecialty, but generally, the expectation is that physicians take the recertifying exam every 10 years (or less).20,23-26 In 2014, regulations changed to require testing every 2 to 4 years with the performance of practice improvement modules. ${ }^{26}$ Practice improvement modules used a combination of healthcare informatics and quality improvement to help physicians use data within their own practice to inform decision making and identify areas for improvement. ${ }^{26} \mathrm{~A}$ model similar to this, which uses formative but comprehensive assessment to help learners better identify their actual knowledge needs with subsequent engagement in deficient areas, could move our profession closer to active engagement in CE and objective measurements of continued competence.

Certainly, there are some limitations to using an actual knowledge assessment to measure competence. ${ }^{27}$ We know that test taking and cognitive knowledge alone are among the weakest measures of competence, as compared to job simulation or job observation. ${ }^{27}$ However, physicians have found direct relationships between competency exam performance and high quality AT care. ${ }^{28,29}$ Also, some suggest that medical knowledge is an essential element in clinical reasoning, supporting the translation of undifferentiated symptoms into diagnoses. ${ }^{30}$ That said, we can improve the relevance of assessments by ensuring clinical relevance and psychometric validity.

\section{Selection of CE Opportunities}

Previous research on selection factors for $\mathrm{CE}$ indicates that athletic trainers select sessions based on cost, location, applicability to their current patients and/or clinical practice setting, and their perceived area of weakness. ${ }^{31-33}$ However, we know from this study and a collection of research on perceived knowledge and self-efficacy that individuals are not able to accurately identify their gaps in knowledge and skills performance. ${ }^{3-6,13}$ Therefore, an external assessment of knowledge and skills is necessary to help guide clinicians in their pursuit of $\mathrm{CE}$ to ensure they maintain competence and develop advanced skills, especially as the standards of practice evolve. This aligns with the IOM's core competency regarding quality improvement. The IOM expects that clinicians are assessing the quality within their system (e.g., patients, staff, environment), the process of healthcare (e.g., interactions between clinicians and patients), and the outcomes (e.g., evidence about the change in the patient's health status). ${ }^{2}$ On the most basic level, athletic trainers should be assessing their knowledge to ensure they maintain entry-level competency. Athletic trainers should also be using measures to assess patient outcomes and compare those outcomes to peers within their practice setting. This allows athletic trainers to ensure high quality patient care and for the further identification of weaknesses within their care. If we consider Miller's pyramid of competence, using a knowledge assessment allows an individual to gauge how much they know on a specific topic. ${ }^{21}$ Chart reviews and measuring and assessing patient outcomes would be at the highest level, where we are assessing one's ability to "do" a given skill or task. The combination will provide valuable information to guide athletic trainers' CE opportunities. 


\section{LIMITATIONS}

Participants who are actively engaged in the CE process and place high value on CE likely self-selected into the study. Therefore, our sample may only be representative of highly engaged practitioners. Additionally, if a participant chose not to answer a question on the knowledge assessment, we assumed they did not know the answer to that question and marked it as an incorrect response. This could have impacted their percent correct within a specific domain and likely impacted the correlational analyses.

\section{FUTURE RESEARCH}

Future research should explore an alternative mechanism of CE that guides clinicians to sessions and conferences based on knowledge gaps that have been identified via low-stakes assessments and a review of patient outcomes. Examining this approach to CE should focus on changes in patient outcomes following the CE session(s). Researchers would then be able to compare patient outcomes between the current method of CE and an alternative model and determine which improves patient care.

\section{CONCLUSIONS AND IMPLICATIONS}

Athletic trainers and the health professions should consider an alternative method for identifying gaps in knowledge and skills to guide CE to maintain competence, such as formative assessments of knowledge and skills. Perceived knowledge and self-efficacy are not effective means of identifying gaps in knowledge and skills. Guiding clinicians to pursue CE in their areas of weakness that were identified by external means of assessment will ensure they maintain competence across all domains of athletic training. This will allow for improved alignment with the IOM core competencies of quality improvement and evidence-based practice, as well as theoretically improve patient outcomes, consistent with literature in physician practice.

\section{REFERENCES}

1. Board of Certification: Continuing Education. In. Omaha, NE: Board of Certification; 2017.

2. Knebel E, Greiner AC. Health professions education: A bridge to quality. National Academies Press; 2003.

3. Eberman LE, Tripp BL. Effect of performance feedback in perceived knowledge and teh likelihood to pursue continuing education. Athl Train Educ J. 2011;6(2):69-75.

4. Edler JR, Eberman LE, Kahanov L, Roman C, Mata H. Knowledge of Athletic Trainers Regarding Airway Adjuncts. Athl Train Educ J. 2015;10(2):164-169.

5. Edwards SD, Eberman LE, Peterson RC, Games KE. Certified athletic trainers' knowledge of posterolateral corner injuries. J Athl Train. 2015:50(6 Supplement);S-203.

6. Neil ER, Games KE, Kahanov L, Eberman LE. Knowledge of athletic trainers and emergency personnel regarding management of the spine injured athlete. Athl Train Educ J. (In Press).

7. Baxley SG, Brown ST, Pokorny ME, Swanson MS. Perceived competence and actual level of knowledge of diabetes mellitus among nurses. J Nurses Staff Dev. 1997;13(2):93-98.

8. Chan MF, Zang YL. Nurses' perceived and actual level of diabetes mellitus knowledge: results of a cluster analysis. $J$ Clin Nurs. 2007;16(7B):234-242.

9. Drass JA, Muir-Nash J, Boykin PC, Turek JM, Baker KL. Perceived and actual level of knowledge of diabetes mellitus among nurses. Diabetes Care. 1989;12(5):351-356.

10. el-Deirawi KM, Zuraikat N. Registered nurses' actual and perceived knowledge of diabetes mellitus. J Nurs Staff Dev. 2001;17(1):5-11.

11. Lehna C, Myers J. Does nurses' perceived burn prevention knowledge and ability to teach burn prevention correlate with their actual burn prevention knowledge? J Burn Care Res. 2010;31(1):111-120.

12. Naughton CA, Friesner DL. Comparison of pharmacy students' perceived and actual knowledge using the Pharmacy Curricular Outcomes Assessment. Am J Pharm Educ. 2012;76(4):63.

13. Youngquist ST, Henderson DP, Gausche-Hill M, Goodrich SM, Poore PD, Lewis RJ. Eberm. Acad Emerg Med. 2008;15(12):1295-1303.

14. Bandura A. Self-efficacy: toward a unifying theory of behavioral change. Psychol Rev. 1977;84(2):191.

15. Cuppett MM. Self-perceived continuing education needs of certified athletic trainers. J Ath/ Train. 2001;36(4):388.

16. National Athletic Trainers' Association. Membership Statistics. In. Dallas, TX: National Athletic Trainers' Association; 2017.

17. National Athletic Trainers' Association. Athletic Training Educational Competencies (5th Ed). In. Dallas, TX: National Athletic Trainers' Association; 2011.

18. Board of Certification. Continuing Education Resources. In. Omaha, NE: Board of Certification; 2017.

19. Board of Certification and Commission on Accreditation of Athletic Training Education. Crosswalk Analysis: Role Delineation Study/Practice Analysis 6th ed. vs. Athletic Training Education COmpetencies, 5th ed. 2013. 
20. Kak N BB, Cooper M. Measuring the competence of healthcare providers. Operations Research Issue Paper 2(1). 2001. Published for the U.S. Agency of International Development (USAID) by the Quality Assurance (QA) Project. In. Bethesda, MD.2001.

21. Miller GE. The assessment of clinical skills/competence/performance. Acad Med. 1990;65(9):S63-67.

22. Wass V, Van der Vleuten C, Shatzer J, Jones R. Assessment of clinical competence. The Lancet. 2001;357(9260):945-949.

23. O'Neill TR, Puffer JC. Maintenance of certification and its association with the clinical knowledge of family physicians. Acad Med. 2013;88(6):780-787.

24. Peabody MR, O'neill TR, Puffer JC. Performance on the Maintenance of Certification for Family Physicians (MC-FP) examination: comparison of initial certifiers with experienced physicians. JABFP. 2015;28(2):294-295.

25. Peterson LE, Blackburn B, Peabody M, O'neill TR. Family Physicians' Scope of Practice and American Board of Family Medicine Recertification Examination Performance. JABFP. 2015;28(2):265-270.

26. Teirstein PS, Topol EJ. The role of maintenance of certification programs in governance and professionalism. JAMA. 2015;313(18):1809-1810.

27. Reid RO, Friedberg MW, Adams JL, McGlynn EA, Mehrotra A. Associations between physician characteristics and quality of care. Arch Intern Med. 2010;170(16):1442-1449.

28. Cassel C, Holmboe ES. Professional standards in the USA: overview and new developments. Clinical Med. 2006;6(4):363-367.

29. Pham HH, Schrag D, Hargraves JL, Bach PB. Delivery of preventive services to older adults by primary care physicians. JAMA. 2005;294(4):473-481.

30. Marco CA, Counselman FL, Korte RC, Russ CM, Whitley CT, Reisdorff EJ. Emergency physicians maintain performance on the American Board of Emergency Medicine continuous certification (ConCert) examination. Acad Emerg Med. 2014;21(5):532-537.

31. Walker SE, Pitney WA, Lauber CA, Berry D. An exploration of athletic trainers' perceptions of the continuing education process. Internet Journal of Allied Health Sciences and Practice. 2008;6(2):5.

32. Armstrong KJ, Weidner TG. Preferences for and barriers to formal and informal athletic training continuing education activities. J Athl Train. 2011;46(6):680-687.

33. Hughes BJ. Identifying attitudes and deterring factors toward continuing education among certified athletic trainers. Internet Journal of Allied Health Sciences and Practice. 2005;3(1):2. 